Please do not remove this page

RMIT

UNIVERSITY

\title{
Prediction of the effect of porous sound-absorbing material inside a coupled plate cavity system
}

Liu, Zhengqing; Fard, Mohammad; Davy, John

https://researchrepository.rmit.edu.au/esploro/outputs/9921860472101341/filesAndLinks?institution=61RMIT_INST\&index=null

Liu, Z., Fard, M., \& Davy, J. (2016). Prediction of the effect of porous sound-absorbing material inside a coupled plate cavity system. International Journal of Vehicle Noise and Vibration, 12(4), 314-330. https://doi.org/10.1504/IJVNV.2016.081825

Document Version: Accepted Manuscript

Published Version: https://doi.org/10.1504/IJVNV.2016.081825

Repository homepage: https://researchrepository.rmit.edu.au

Copyright (c) 2016 Inderscience Enterprises Ltd.

Downloaded On 2023/04/26 12:34:14 +1000 
Thank you for downloading this document from the RMIT Research Repository.

The RMIT Research Repository is an open access database showcasing the research outputs of RMIT University researchers.

RMIT Research Repository: http://researchbank.rmit.edu.au/

\author{
Citation: \\ Liu, Z, Fard, M and Davy, J 2016, 'Prediction of the effect of porous \\ sound-absorbing material inside a coupled plate cavity system', International Journal \\ of Vehicle Noise and Vibration, vol. 12, no. 4, pp. 314-330.
}

See this record in the RMIT Research Repository at:

https://researchbank.rmit.edu.au/view/rmit:43315

Version: Accepted Manuscript

\title{
Copyright Statement:
}

(C) 2016 Inderscience Enterprises Ltd.

Link to Published Version:

https://doi.org/10.1504/IJVNV.2016.081825 


\title{
Prediction of the effect of porous sound absorbing material inside a coupled plate cavity system
}

\author{
Zhengqing Liu*, Mohammad Fard and \\ John Laurence Davy \\ Noise and Vibration Group, \\ School of Engineering (SENG), \\ RMIT University, Melbourne 3001, Victoria, Australia \\ Email: liu.zhengqing@rmit.edu.au \\ Email: mohammad.fard@rmit.edu.au \\ Email: john.davy@rmit.edu.au \\ *Corresponding author
}

\begin{abstract}
This paper predicts the acoustic properties of the porous sound absorbing material in a box cavity by conducting a FEM (Finite Element Method) analysis, and it verifies the estimated acoustic properties using an appropriate experimental method. The cavity is a rectangular box with five rigid walls and one flexible wall which is an aluminium plate. The porous sound absorbing material is attached to the inner surface of the plate, in order to modify the coupling between the plate inner surface and the air inside the box. The plate is mechanically excited by using an electromagnetic shaker, which is imitating structure-borne noise. The generated noise is recorded by using pressure microphones at the different locations inside the box. The results show that there is good agreement between the FEM prediction and the measurement for the acoustic response at different locations inside the rectangular box. Sound pressure peaks due to cavity modes are effectively reduced by adding porous sound absorbing material. Furthermore, sound level in the cavity is reduced by a similar amount in both the numerical simulation and the measurement, when a porous sound absorbing material is added. The developed FEM model is used to characterize the effects of porous sound absorbing material in reducing the structure-borne radiated noise.
\end{abstract}

Keywords: porous sound absorbing material; coupled plate cavity system; finite element method; acoustic response.

Reference to this paper should be made as follows: Liu, Z., Fard, M. and Davy, J.L (2016) 'Prediction of the effect of porous sound absorbing material inside a coupled plate cavity system', Int. J. Vehicle Noise and Vibration, Vol. $\mathrm{x}$, No. $\mathrm{x}, \mathrm{pp} . \mathrm{xxx}-\mathrm{xxx}$.

Biographical notes: Zhengqing Liu is a $\mathrm{PhD}$ student in Mechanical Engineering at School of En gineering (SENG), RMIT University (Melbourne, AUSTRALIA). He received his BEng degree in Automotive Engineering at the School of Aerospace, Mechanical, and Manufacturing Engineering (SAMME), RMIT University (Melbourne, AUSTRALIA) in 2013. His PhD specialization is in the field of Vehicle Noise, Vibration, and Harshness $(\mathrm{NVH})$ and Interior Acoustic Prediction. He has also actively pursued a project focused on composite Micro-Perforated Panel (MPP) structures fabricated by $3 \mathrm{D}$ printing technology in the field of Additive Manufacturing.

Copyright $\odot$ 200x Inderscience Enterprises Ltd. 


\begin{abstract}
Mohammad Fard is an Associate Professor at School of En gineering (SENG), RMIT University (Melbourne, AUSTRALIA). He received his PhD from Tohoku University, Japan in 2003. He was a Senior Vehicle Body Design Engineer at Nissan Motor Company, Japan, for six years. He joined RMIT University, Australia as a Senior Lecturer in 2009. He developed the Laboratory of Human Response to Vibration in the School of Engineering (SENG), RMIT University. His current researches include computational modelling and analy sis of vehicle body noise and vibration, and the effects of vibration on human body discomfort and fatigue.

John Laurence Davy is a Professor in the School of Science, RMIT University (Melbourne, AUSTRALIA). His research interests are the prediction of diffuse field sound insulation, the directivity of sound insulation, the directivity of the radiation of sound from openings, reverberant and anechoic sound fields, microphone turbulence screens, urban noise and building acoustic measurements. He received his BSc from La Trobe University, Australia. He received his $\mathrm{PhD}$ from the Australian National University, Australia.
\end{abstract}

\title{
1 Introduction
}

Porous sound absorbing materials are used extensively in the design of vehicle compartments to provide sound absorption and to improve sound transmission losses through vehicle body panels. They are capable of reducing the noise reflections and improving the speech intelligibility in the passenger compartments. In other words, they reduce the standing waves to enhance the cabin sound quality. Predicting the effect of porous sound absorbing materials on the control of structure-borne radiated noise into a vehicle compartment is still challenging. This is mainly due to the fact that most of the porous sound absorbing materials are composites, and they are heterogeneous with a random fibrous skeleton. Hence, understanding the influence of the porous sound absorbing material in a vibro-acoustic coupling system by using an appropriate simple acoustic model is desirable in designing, analysing and refining the acoustic behaviour of the vehicle interior trims.

The structure-borne noise radiated from a vibrating vehicle body into the passenger compartments is usually simplified and modelled by using a coupled plate cavity system. The vibro-acoustic response of a cavity-backed plate system has been studied for the past few decades, through various analytical and experimental methods. Among early works of the vibro-acoustic response of a coupled plate cavity system are those reported by Dowell and Voss (1963), Pretlove (1965a, 1965b), Guy and Bhattacharya (1973), Pretlove and Craggs (1970), Dowell et al. (1977), Guy (1979), and Qaisi (1988). They have presented full theoretical solutions for the free and forced response of a vibroacoustic coupled system. The fundamental theories and experimental validations of the noise propagation from the vibrating plate into a cavity have been well reviewed and presented by Pan and Bies (1990a, 1990b). They have pointed out that the earlier approach was only suitable for weak coupling; the velocity continuity on the coupling interface cannot be satisfied by the Modal Coupling Theory (Pope, 1971; Keltie and Peng, 1987). Moreover, the interaction between the plate and the air cavity, and the vibro-acoustic analysis of the coupled system have been further investigated (Lee, 2002; 
Citarella et al., 2007; Seifzadeh et al., 2014). The early research aimed at progressively improving the theoretical knowledge of and the physical insight into the vibro -acoustic coupling problems (Li and Cheng, 2006; Du et al., 2011, 2012; Tanaka et al., 2012).

The acoustic design of vehicle interior trims requires a good understanding of the mechanis ms governing the vibrational and acoustical behaviour of a coupled plate cavity system, together with an acoustic characterization of porous sound absorbing materials. The major theoretical achievement in the history of vibro-acoustical behaviour of porous sound absorbing material was established by Biot (1956a, 1956b, 1962). The FE formulation regarding the displacement of the solid-phase (fibrous skeleton) and the airphase (fluid in the pore) for a porous sound absorbing material was done by Zienkiewicz and Shiomi (1984), Kang and Bolton (1995), Easwaran et al. (1996). The model was also modified and developed by Johns on et al. (1987), and further extended by Champoux and Allard (1991, 1992, 2009), Lafarge et al. (1997). The so-called Johnson-ChampouxLafarge-Allard (JCLA) model uses the equivalent fluid approaches with the complex effective density, speed of sound, characteristic impedance, and propagation constant to describe the porous sound absorbing material. The equivalent fluid approaches were frequently conducted in FEM analysis (Craggs, 1978; Panneton et al., 1995). Moreover, the analytical study of the role of porous sound absorbing material on the noise control inside a cavity backed plate was presented by Atalla et al. (2003), and Bécot et al. (2006, 2011). They aimed to investigate the validity of the vibro-acoustic model in the case of a plate coated with a porous sound absorbing material and coupled to a rigid-walled cavity for the prediction of the low-frequency acoustic sound pressure response. The coupling between the plate structure, sound absorbing material and the air cavity was presented by Atalla and Panneton (1996).

The literature mentioned above provided several methods to predict the acoustic response of a coupled plate cavity system and used a general method to model the acoustic properties of sound absorbing materials. However, the effect of a porous sound absorbing material inside a coupled plate and cavity system has not been well presented, and not well validated by using the experimental method (Liu et al., 2015a; 2016a). The literature lacks the modelling of the acoustic properties of a coupled plate cavity system containing porous sound absorbing material due to structure-borne radiated noise. Hence, it is necessary to develop an acoustic model containing porous sound absorbing material to predict the acoustic properties of interior trim materials during the early design phase. The primary objective of this paper is to study the acous tic performance of porous sound absorbing material on the noise level inside an enclosed rectangular box cavity, by using a numerical simulation and validating it by an appropriate experimental method.

\section{Experiment}

A rectangular box cavity was designed to investigate the effect of the porous sound absorbing material on the noise level in a coupled plate cavity system. Figure 1 (a) shows a well-sealed rectangular box cavity that was developed in the laboratory. The inner air cavity volume has the size of $L_{x}=450 \mathrm{~mm}, L_{y}=300 \mathrm{~mm}$ and $L_{z}=400 \mathrm{~mm}$. The box has five rigid walls and one flexible aluminium plate on the end wall. The rigid walls were made of $25 \mathrm{~mm}$ Tempered Perspex, and the flexible alu minium plate was carefully bolted to the box all around the edges of the plate. The size of the alumin ium plate was $L_{x}=450$ $\mathrm{mm}, L_{y}=300 \mathrm{~mm}$ and the thickness was $5 \mathrm{~mm}$. These relative dimensions were chosen in 
order to make sure that the ratio of any two lengths was not a small integer ratio. The overall size was chosen in order to to keep the box structurally rigid with the materials available. The rectangular shape was chosen so that the modes of the air cavity and of the aluminiu m plate could be analytically calculated. Because of the difference in thickness, the bending stiffness of the $5 \mathrm{~mm}$ aluminium plate will be about one quarter of the bending stiffness of the $25 \mathrm{~mm}$ Perspex walls.

The plate was mechanically excited by using a miniature electrodynamic shaker (Model 2007E, The Modal Shop Inc.) and a stringer that was carefully glued to the center of the aluminum plate. The shaker was generating a random signal with a point force equal to $1.0 \mathrm{~N} \mathrm{rms}$ value. In this experiment, pressure field mic rophones (Array microphone type 4957, Brüel \& Kjær) for random incidence, and B\&K Pulse LabShop were used to measure the SPL in a small rigid walled box cavity. The SPL in the cavity was measured at two different locations; one (Mic\#1) at location of $x=170 \mathrm{~mm}, y=125 \mathrm{~mm}, z=150$ $\mathrm{mm}$, and the other (Mic\#2) at location of $x=375 \mathrm{~mm}, y=110 \mathrm{~mm}, z=165$. The location of the microphones were randomly selected, and the acoustic sound pressure response was analysed up to $500 \mathrm{~Hz}$.

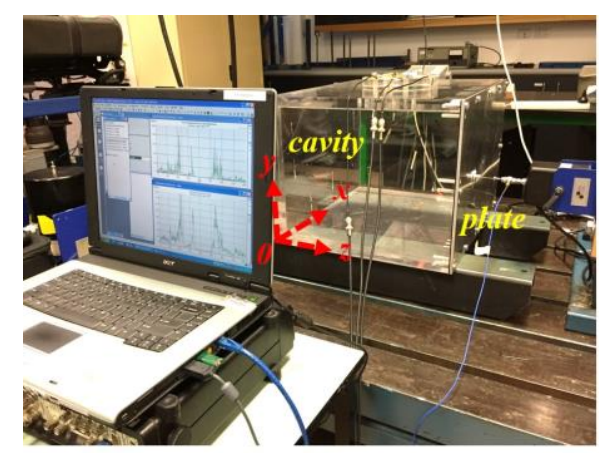

(a)

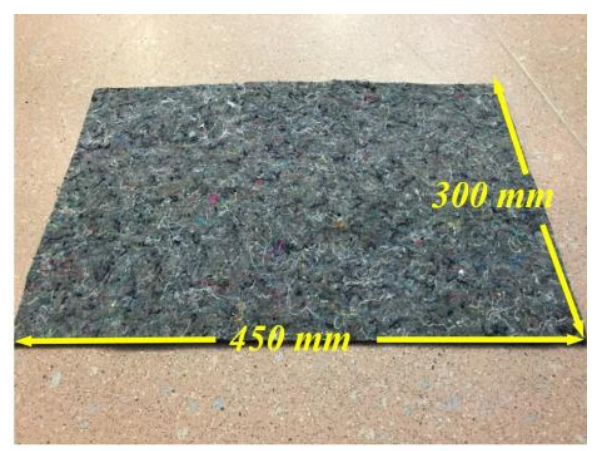

(b)

Figure 1 (a) acoustic rectangular box cavity experiment setup in the laboratory; (b) a $5 \mathrm{~mm}$ nonwoven porous sound absorbing material sample, the size is $L_{x}=450 \mathrm{~mm}$, and $L_{y}=300$ $\mathrm{mm}$.

The porous sound absorbing material ( $5 \mathrm{~mm}$ Nonwoven Fabrics Linen) was cut down to $450 \mathrm{~mm}$ by $300 \mathrm{~mm}$ to fit the size of the alu minum plate as shown in Figure 1 (b). It has an average density of $140.10 \mathrm{~kg} / \mathrm{m}^{3}$, flow resistivity $\sigma=181000 \mathrm{~N} . \mathrm{s} / \mathrm{m}^{4}$, tortuosity $\alpha_{\infty}=$ 2.9 , porosity $\phi=0.98$, viscous characteristic lengths $\Lambda=0.000112 \mathrm{~m}$, and thermal characteristic lengths $\Lambda^{\prime}=0.000224 \mathrm{~m}$. These acoustic material properties were well studied by Liu et al. (2015b, 2016b).

The measurement was carried out in two conditions: one with the porous sound absorbing material attached to the inner surface of the plate and one without it. The porous sound absorbing material was carefully glued on the inner surface of the aluminum plate, and the aluminum plate-backed porous sound absorbing material was then carefully bolted to the box all around the edges of the plate. It should be noted that the sound pressure was 
measured at the same microphone locations (Mic\#1 and Mic\#2) with and without the porous sound absorbing material.

\section{Theoretical formulation}

The analytical model is composed of a coupled plate and cavity system, in which a porous sound absorbing material covers the inner surface of the plate. Figure 2 shows the schematic of a coupling system that consists of three different domains. They are the elastic domain $\left(\Omega_{\mathrm{e}}\right)$ for a rectangular flexible plate, the porous domain $\left(\Omega_{\mathrm{p}}\right)$ for a porous sound absorbing material, and the acoustic domain $\left(\Omega_{\mathrm{a}}\right)$ for the air inside the box cavity. In this study, the edges all around the flexible plate are assumed to be a simply supported boundary conditions. Simply supported boundary conditions are assumed because experimentally it is difficult to achieve clamped boundary conditions. The experimental boundary conditions are likely to be closer to simply supported boundary conditions than to clamped boundary conditions. The plate is excited by a point force, $F$ normal to the plate as shown in Figure 2. The vibrating plate will generate sound waves and radiate into the box cavity through the porous sound absorbing material.

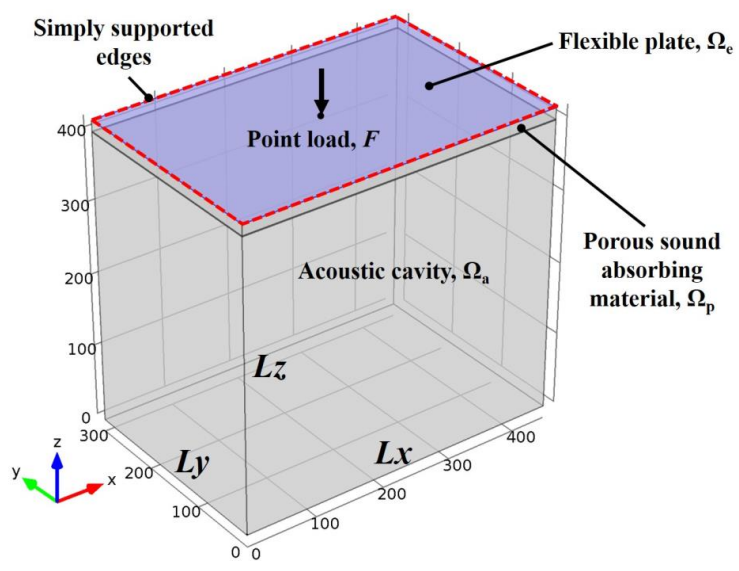

Figure 2 Schematic of a coupled plate cavity sy stem with a porous sound absorbing material.

In this section, the formulations of the coupling system are presented. The model of the coupling system is performed using the FEM, in which the elastic domain and acoustic domain use the classical formulations (Dowell and Voss, 1963; Pretlove, 1965a, 1965b; Guy and Bhattacharya, 1973; Pretlove and Craggs, 1970), and the porous sound absorbing material is using the equivalent fluid formulations (Johnson et al. 1987; Champoux and Allard, 1991, 1992, 2009; Lafarge et al., 1997; Panneton, 2007).

\subsection{Vibro-acoustic coupling model}


The plate is assumed to satisfy the classical small deflection theory, and the following equation gives the differential equation of motion governing the trans verse displacement response of a thin rectangular plate (Cremer and Heckl, 1988):

$$
D \nabla^{4} w(x, y, t)+\rho h \frac{\partial^{2} w(x, y, t)}{\partial t^{2}}=p(x, y, z, t)-F
$$

where $D$ is bending stiffness, which is related to Young's modulus $E$ and Poisson's ratio $v$ of the material for elastic plate, and it can be calculated by $D=E h^{3} / 12\left(1-v^{2}\right) . \nabla^{4}$ is the Biharmonic differential operator, $\rho$ and $h$ indicate the density and thickness of the elastic plate, $w(x, y, t)$ denotes the displacement of the flexible portion for the plate in the outward normal direction $\overrightarrow{\boldsymbol{n}}$ of the air cavity surface, $p(x, y, z, t)$ is the acoustic sound pressure fluctuation inside the air cavity at any time $t$. On the other hand, the simply supported boundary conditions can be presented by (Oldham and Hillarby, 1990):

$$
\begin{aligned}
& w(x, y)=0, \quad \frac{\partial^{2} w}{\partial x^{2}}=0 \text { for } \quad x=0 \text { and } x=L_{x} \\
& w(x, y)=0, \quad \frac{\partial^{2} w}{\partial y^{2}}=0 \quad \text { for } \quad y=0 \text { and } y=L_{y}
\end{aligned}
$$

where $w(x, y)$ denotes the displacement on the plate. $L_{x}$ and $L_{y}$ are, respectively, the length and width of the flexible plate.

It is well known that for a simple supported thin rectangular plate, the resonances $\left(f_{m, n}\right)$ and mode shapes $\left(\phi_{m, n}\right)$ are given by (Cremer and Heckl, 1988):

$$
\begin{aligned}
& f_{m, n}=\sqrt{\frac{D}{\rho h}}\left(\left(\frac{m \pi}{L_{x}}\right)^{2}+\left(\frac{n \pi}{L_{y}}\right)^{2}\right) \\
& \phi_{m, n}=A_{m, n} \sin \left(\frac{m \pi x}{L_{x}}\right) \sin \left(\frac{n \pi y}{L_{y}}\right)
\end{aligned}
$$

where $A_{m, n}$ is an arbitrary constant determined by the initial conditions, $m$ is the modal index along the $x$-axis, and $n$ is the modal index along the $y$-axis.

On the other hand, the air flu id in the acoustic cavity is considered to be compressible, irrotational and inviscid, and the sound pressure inside the cavity satisfies the classical wave equation, and it is given by (Hopkins, 2007):

$$
\nabla^{2} p(x, y, z, t)-\frac{1}{c_{0}^{2}} \frac{\partial^{2} p(x, y, z, t)}{\partial t^{2}}=0
$$


where $\nabla^{2}$ is the Laplacian operator, $c_{0}$ is the speed of sound in the air. The associated boundary conditions on the rigid cavity walls are given by $\partial P / \partial \overrightarrow{\boldsymbol{n}}=0$, and by $\partial P / \partial \overrightarrow{\boldsymbol{n}}=-$ $\rho_{0} \partial^{2} w(x, y, t) / \partial t^{2}$ on the flexible aluminum plate, $\rho_{0}$ is the desity of the air inside the box cavity. The natural frequencies $\left(f_{i, j, k}\right)$ and mode shapes $\left(\psi_{i, j, k}\right)$ of a rigid walled rectangular acoustic cavity are given by (Elwali et al., 2012):

$$
\begin{aligned}
& f_{i, j, k}=\frac{c_{0}}{2} \sqrt{\left(\frac{i \pi}{L_{x}}\right)^{2}+\left(\frac{j \pi}{L_{y}}\right)^{2}+\left(\frac{k \pi}{L_{z}}\right)^{2}} \\
& \psi_{i, j, k}=A_{i, j, k} \cos \left(\frac{i \pi x}{L_{x}}\right) \cos \left(\frac{j \pi y}{L_{y}}\right) \cos \left(\frac{k \pi z}{L_{z}}\right)
\end{aligned}
$$

where $A_{i, j, k}$ is an arbitrary constant determined by initial conditions, $i, j, k$ are the modal indices along the $x, y, z$-axis of the rectangular acoustic cavity, respectively.

\subsection{Porous sound absorbing material model}

The porous sound absorbing material is treated as a equivalent fluid model with acoustic material properties given by Liu et al. (2015b). The propagation of noise in a porous sound absorbing material is fully described by wave impedance and wave number. For the noise propagating in the air without dissipation, these quantities are independent of the frequency of excitation. The complex effective density and sound velocity is used to describe the viscosity effects as well as the thermal exchanges with the connecting solid skeleton. The governing equation then can be re-written as (Panneton, 2007):

$$
\Delta p_{p} \frac{1}{\omega^{2} \tilde{\rho}(\omega)}+\frac{1}{K(\omega)} p_{p}=0
$$

where $p_{p}$ is the complex pressure amplitude, $K(\omega)$ and $\tilde{\rho}(\omega)$ are the bulk modulus and complex effective density for the porous sound absorbing material, respectively. These can be obtained from the following equations (Johnson et al., 1987; Champoux and Allard, 1991, 1992, 2009; Lafarge et al., 1997; Liu et al., 2016):

$$
\begin{aligned}
& K(\omega)=\gamma_{o} p_{o} /\left[\left(\gamma_{o}-\left(\gamma_{o}-1\right)\left(1+\frac{8 \eta}{i \omega P_{r} \rho_{f} \Lambda^{\prime 2}} \sqrt{1+\frac{i \omega P_{r} \rho_{f} \Lambda^{\prime 2}}{16 \eta}}\right)^{-1}\right)\right] \\
& \tilde{\rho}(\omega)=\alpha_{\infty} \rho_{f}^{2}\left[1+\frac{\sigma \phi}{i \omega \rho_{f} \alpha_{\infty}} G(\omega)\right]
\end{aligned}
$$




$$
G(\omega)=\left(1+i \omega \frac{4 \eta \rho_{f} \alpha_{\infty}^{2}}{\sigma^{2} \Lambda^{2} \phi^{2}}\right)^{1 / 2}
$$

where $\gamma_{0}$ is the specific heat ratio, $p_{0}$ is the ambient fluid pressure, $P_{r}$ is the Prandtl number for the ambient fluid, $\eta$ is the ambient fluid viscosity, and $\rho_{f}$ is the mass density of the fluid inside the porous sound absorbing material. $G(\omega)$ is a complex function that depends on the geometry of the pores. The acoustic properties for a porous sound absorbing material are the airflow resistivity $(\sigma)$, tortuosity $\left(\alpha_{\infty}\right)$, porosity $(\phi)$, viscous characteristic length $(\Lambda)$, and thermal characteristic length $\left(\Lambda^{\prime}\right)$.

\subsection{Coupling conditions}

In this case, the porous sound absorbing material is attached to the inner surface of the aluminium plate and there is continuity between the normal displacement of the aluminium plate and the porous sound absorbing material. The description and the interface between each two domains are presented in Figure 3. The coupling conditions between the flexible plate and the porous sound absorbing material is given by (Yamamoto et al., 2009; Actran 13, user's guide):

$$
u_{e} \mathbf{n}_{e}=u_{p} \mathbf{n}_{p} \quad \text { and } \quad \sigma_{e} \mathbf{n}_{e}=\sigma_{p} \mathbf{n}_{p}
$$

where $u_{e}$ and $u_{p}$ represent the displacement vector of the elastic plate and porous sound absorbing material, respectively, $\sigma_{e}$ and $\sigma_{p}$ are the stress tens or of the elastic plate and the porous sound absorbing material, and $\mathbf{n}$ is either the normal pointing outward from the elastic domain, porous domain or acoustic domain.

On the other hand, the average normal displacement continuity and pressure continuity, for the interface between the porous sound absorbing material and acoustic cavity are given by (Yamamoto et al., 2009; Actran 13, user's guide):

$$
u_{p} \mathbf{n}_{p}=u_{a} \mathbf{n}_{a} \text { and } p_{p}=p_{a}
$$

where $u_{a}, p_{p}$ and $p_{a}$ are, respectively, the displacement vector of the acoustic domain, the acoustic pressure fluctuation of the porous sound absorbing material, and the air fluid acoustic pressure inside the acoustic domain. 


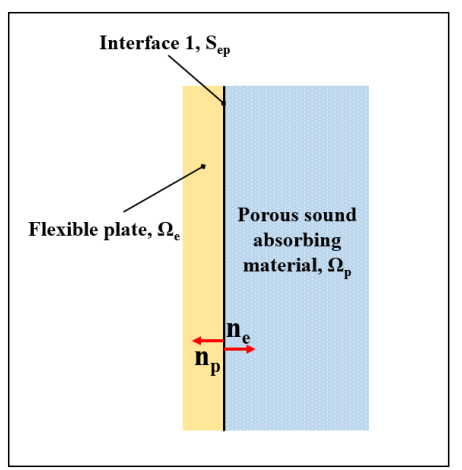

(a)

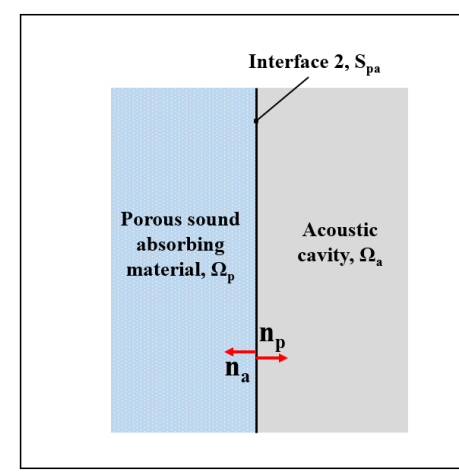

(b)

Figure 3 Schematic of the interfaces between (a) flexible aluminium plate and porous sound absorbing material; (b) porous sound absorbing material and acoustic cavity.

\subsection{Finite element model}

The weak integral form in each domain is discretized by using the FE method. The detail method can be found in Rumpler et al. $(2012,2013)$. The coupled system equation in the matrix form then may be derived as (Yamamoto, et al., 2009; Liu et al., 2015):

$$
\left[\begin{array}{ccc}
K_{e}-\omega^{2} M_{e} & -j \omega C_{e \& p} & 0 \\
-j \omega C_{e \& p}^{T} & K_{p}-\omega^{2} M_{p} & j \omega C_{p \& a} \\
0 & j \omega C_{p \& a}^{T} & K_{a}-\omega^{2} M_{a}
\end{array}\right]\left\{\begin{array}{l}
U_{e} \\
P_{p} \\
P_{a}
\end{array}\right\}=\left[\begin{array}{c}
F \\
0 \\
0
\end{array}\right]
$$

where $M$ and $K$ are the equivalent mass and stiffness matrices for each do main. $C$ are the coupling matrices between each of the two domains. The sound pressure level then can be calculated from the acoustic pressure given by the FE model.

Figure 4 shows the Finite Element (FE) model of the coupled system that was developed in this study. The FE model shows that the noise is generated from an equivalent $1.0 \mathrm{~N} \mathrm{rms}$ point load input applied to the alu min iu m plate at the same location as in the experiment. Simply supported boundary conditions are used for all the plate edges. The output acoustic sound pressure responses are those at nodal\#5 and nodal\#8 in the FE model. They are the same locations as Mic\#1 and Mic\#2 in the experiment. The interface between each two domains are defined, and the weak coupling has been assumed, in which the energy involved in the interaction is much s maller than the energy in each domain. Incompatible meshes are used due to the facts that, the mesh of the plate is guided by the bending wavelength, but the cavity mesh is ruled by the acoustic wavelength (Actran 13, user's guide). 


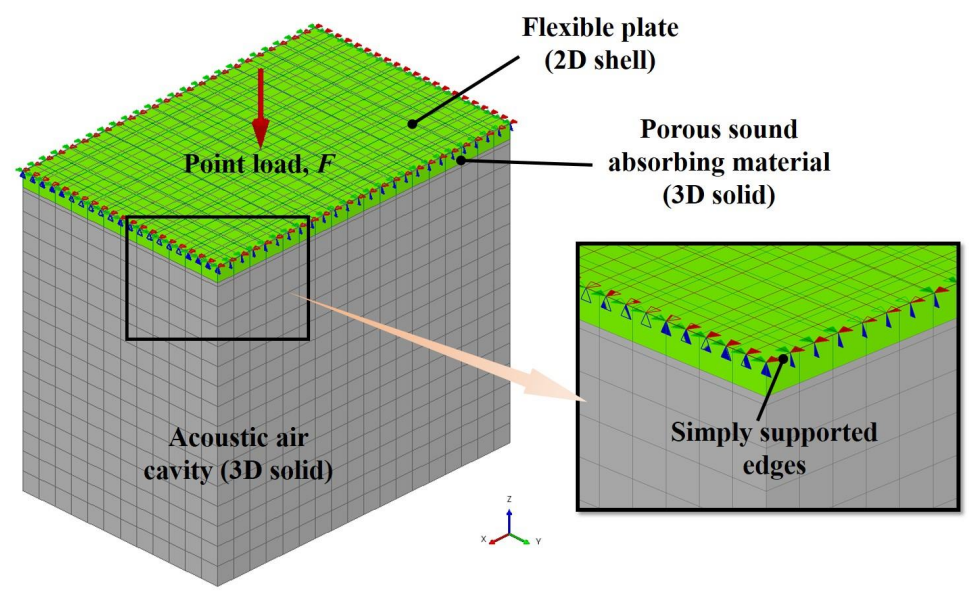

Figure 4 FE model of the coupling system, including a flexible aluminum plate (2-D shell elements), porous sound absorbing material (3-D solid elements), and acoustic air-cavity (3-D solid elements), showing the point load excitation and simply supported edges all around the flexible aluminum plate.

For modelling the thin flexible alu miniu m plate, two-d imensional shell elements are used. The material properties of the aluminiumplate are Young's modulus $E=72$ Gpa, Poisson's ratio $v=0.35$, and density $\rho=2700 \mathrm{~kg} / \mathrm{m}^{3}$. Three-dimensional solid elements are used for modelling both the porous sound absorbing material and the acoustic aircavity. The air-fluid properties are the density $\rho_{0}=1.18 \mathrm{~kg} / \mathrm{m}^{3}$, and the speed of sound $c_{0}$ $=346.13 \mathrm{~m} / \mathrm{s}$, which is calculated from the room temperature of $24.9 \mathrm{C}^{\mathrm{o}}$ (the temperature is measured inside the box of the experimental environment). It should be noted that a constant damping equal to $3 \%$ for the alu min iu m plate and a constant damping of $1 \%$ for the air in the box are used. These values were chosen based on a comparison of the numerical results with measurements.

\section{Results and discussion}

\subsection{The effect of porous sound absorbing material on a coupled system}

In this section, the measured acoustic sound pressure response functions between the exciting force and the SPL inside the acoustic box cavity are obtained, and the effect of the porous sound absorbing material on the coupled plate and cavity system is obtained. Figure 5 shows the measurement results of the effect of the porous sound absorbing material on the sound pressure level of a coupled plate cavity system for Mic\#1 and Mic\#2, res pectively. The peaks indicate that the sound energy transfer from the vibrating plate into the acoustic cavity mainly depends upon the resonant frequencies of the modes of the plate and the acoustic cavity. 


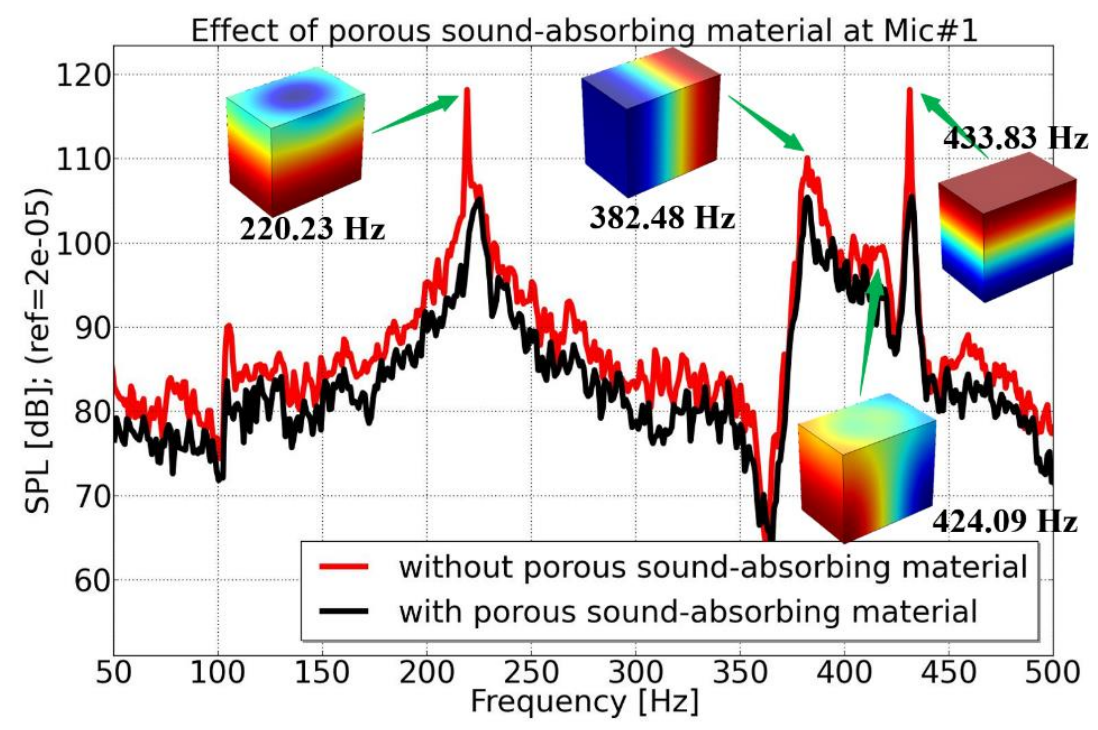

(a)

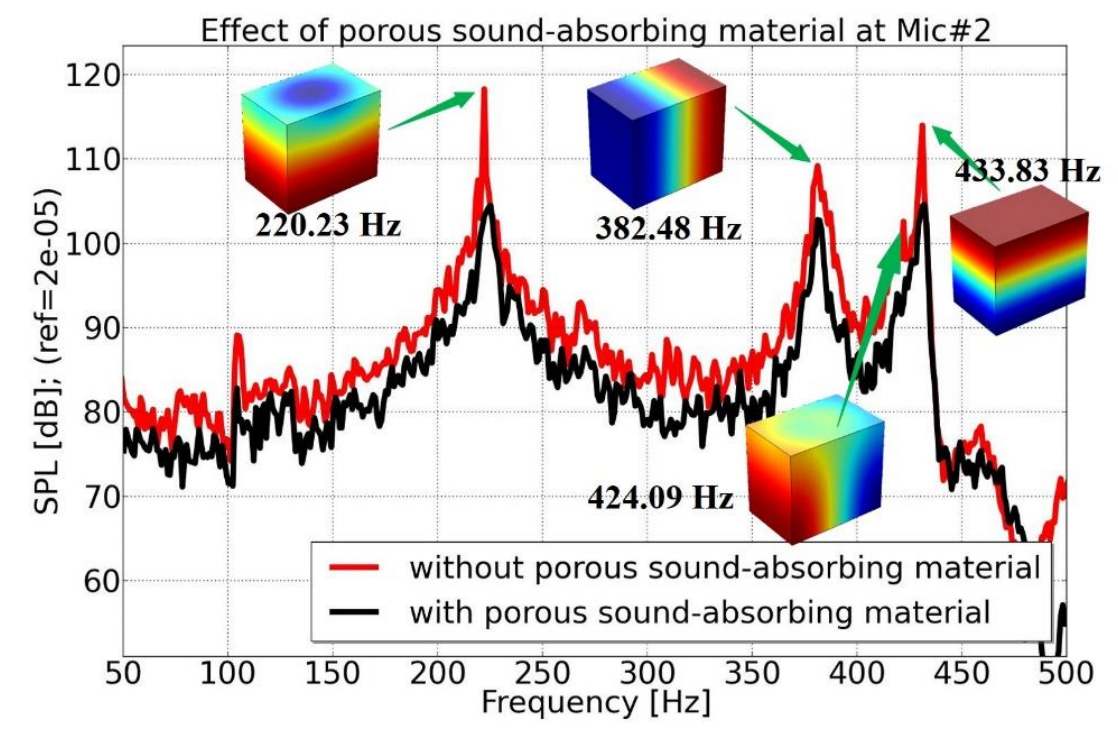

(b)

Figure 5 The effect of the porous sound absorbing material on the coupled plate and cavity system: (a) the sound pressure response of Mic\#1 without and with the porous sound absorbing material; (b) the sound pressure response of Mic\#2 without and with the porous sound absorbing material. The results are obtained from the measurement data.

The obtained results from the two different microphone locations show that the peaks observed at $220.23 \mathrm{~Hz}$ and $424.09 \mathrm{~Hz}$ are due to the plate modes, the peaks at 
$382.48 \mathrm{~Hz}$, and $433.83 \mathrm{~Hz}$ are due to the acoustic cavity modes. It should be noted that the plate and cavity resonant frequencies are obtained from equations (4) and (7). For a weak coupling condition, the differences between the resonant frequencies of the coupled system and the corresponding uncoupled rigid-walled cavity and plate are very small. This is due to the fact that the air-fluid density is very low, and the plate stiffness is relatively high. Thus the radiated sound energy from the vibrating plate is much smaller than the energy in the acoustic cavity. Therefore, the motions of the coupled plate and cavity system are not essentially different from the system that is uncoupled. This confirmed by the experimental results which show that the resonant frequencies of the coupled system with the porous sound absorbing material are only slightly disturbed. This is because of the motion of the plate and porous sound absorbing material normal to their surfaces is very small, and thus the resonant frequencies of the acoustic cavity are not strongly affected.

The results show that the porous sound absorbing material reduces the sound transmission into the acoustic cavity, and it provides a significant reduction of the radiated sound energy compared to when the system is not treated. The peaks of the SPL caused by the plate vibration and cavity modes are reduced by adding porous sound absorbing material. This is due to the fact that, the porous sound absorbing material has a damping effect on the plate displacement, in which the plate vibration energy is dissipated in the form of heat and absorbed by the solid skeleton of the porous sound absorbing material. The noise in the cavity is also reduced by the porous sound absorbing material due to the thermal and viscous effects. It can be concluded that the porous sound absorbing material plays a very important role in the control of the acoustic sound pressure response, especially for the noise reduction in a coupled plate and cavity system. It is difficult to change the sound pressure response characteristics in the low frequency range when the design of the vehicle structure and compartment is fixed. The results obtained from the simple acoustic box experiments and calculations showed that adding sound absorbing material can improve the acoustic performance of the vehicle cabin in the low frequency range.

\subsection{Comparison of results}

To further consolidate the above analyses, comparisons between the experiment data and the results from the FE model are presented. The validation is first performed without porous sound absorbing material to provide a benchmark for further evaluations. Figure 6 shows the comparis on of results between the experimental method and finite element model for the acoustic sound pressure responses at Mic\#1 ( $x=170 \mathrm{~mm}, y=125 \mathrm{~mm}, z=$ $150 \mathrm{~mm})$ and Mic\#2 $(x=375 \mathrm{~mm}, y=110 \mathrm{~mm}, z=165 \mathrm{~mm})$. The results in the figure represent the acoustic sound pressure response in the coupled plate cavity model without the porous sound absorbing material.

The numerical simulation results show good agreement with the corresponding experiment data. The predicted resonant frequencies and their corresponding peak values agree well with the experiment results. The sound pressure response of the experiment data is higher than the FE model in some frequency ranges, but the general trend of the data is still qualitatively predicted. The differences may be because of the influence of environment noise or vibration. It is impossible to make a rigid walled box and vibration is olate it completely from its environment. 


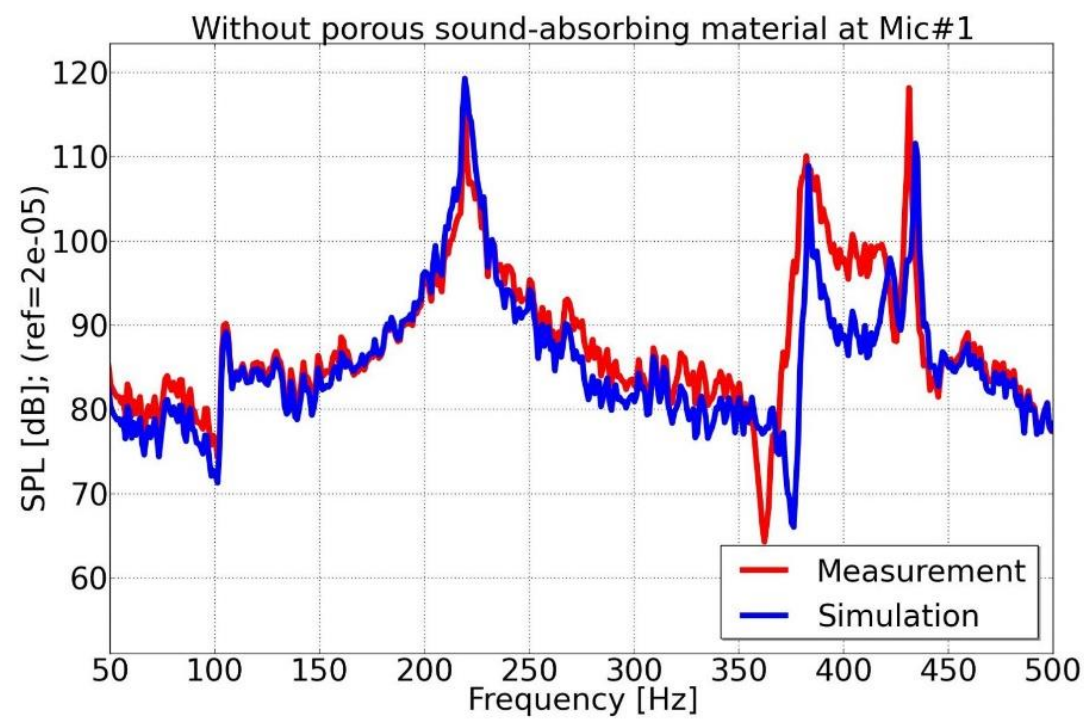

(a)

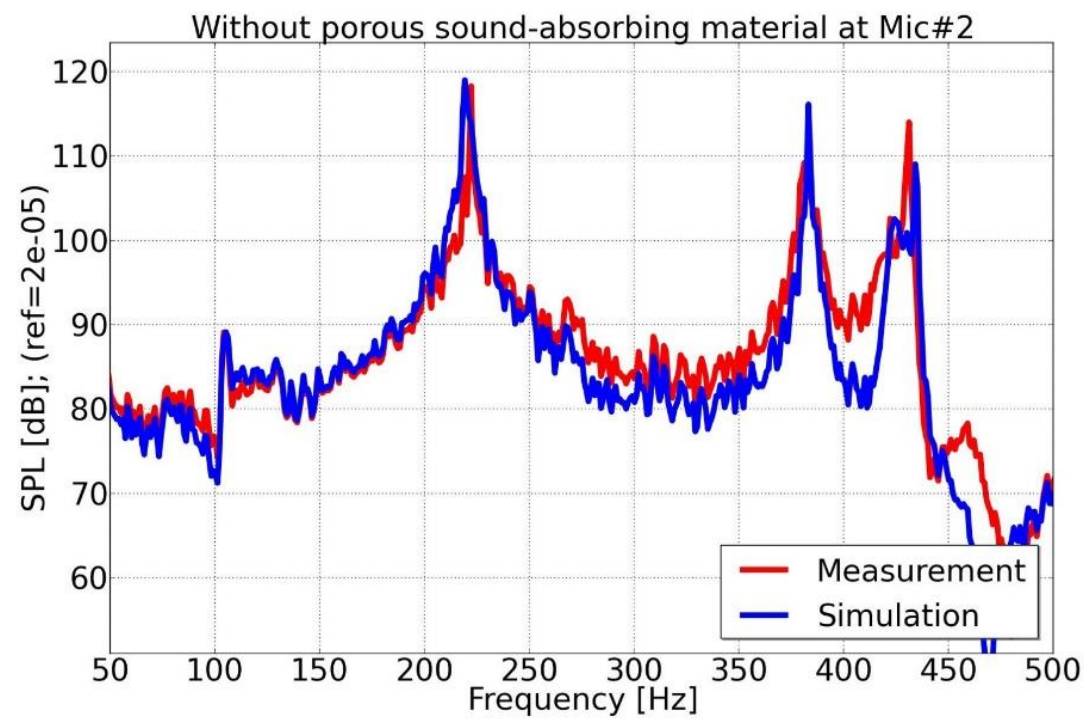

(b)

Figure 6 Comparison of the sound pressure response of the experimental method and the finite element model, for the coupled plate cavity system without porous sound absorbing material: (a) sound pressure response of Mic\#1 to a point force excitation; (b) sound pressure response of Mic\#2 to a point force excitation. 
The experiment results showed that the acoustic sound pressure responses of the coupled plate cavity system are also well predicted in the frequency range from 50 to 500 $\mathrm{Hz}$ when porous sound absorbing material is present. Figure 7 shows the comparison between the experiment results and the numerical simulation when the porous sound absorbing material is attached to the plate.

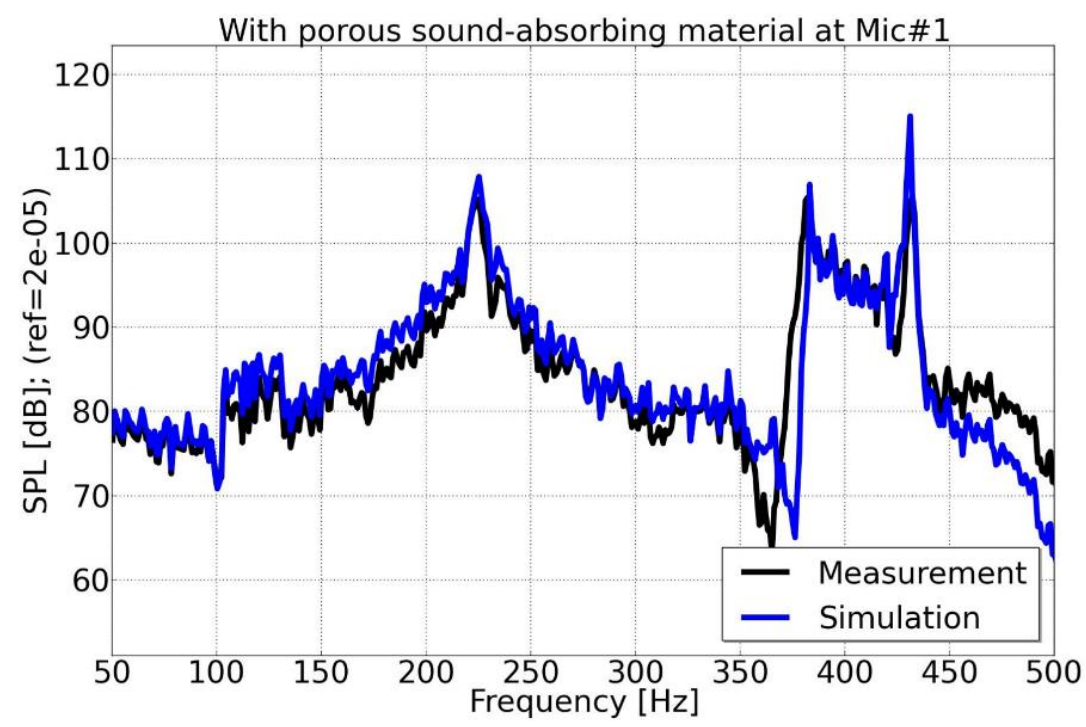

(a)

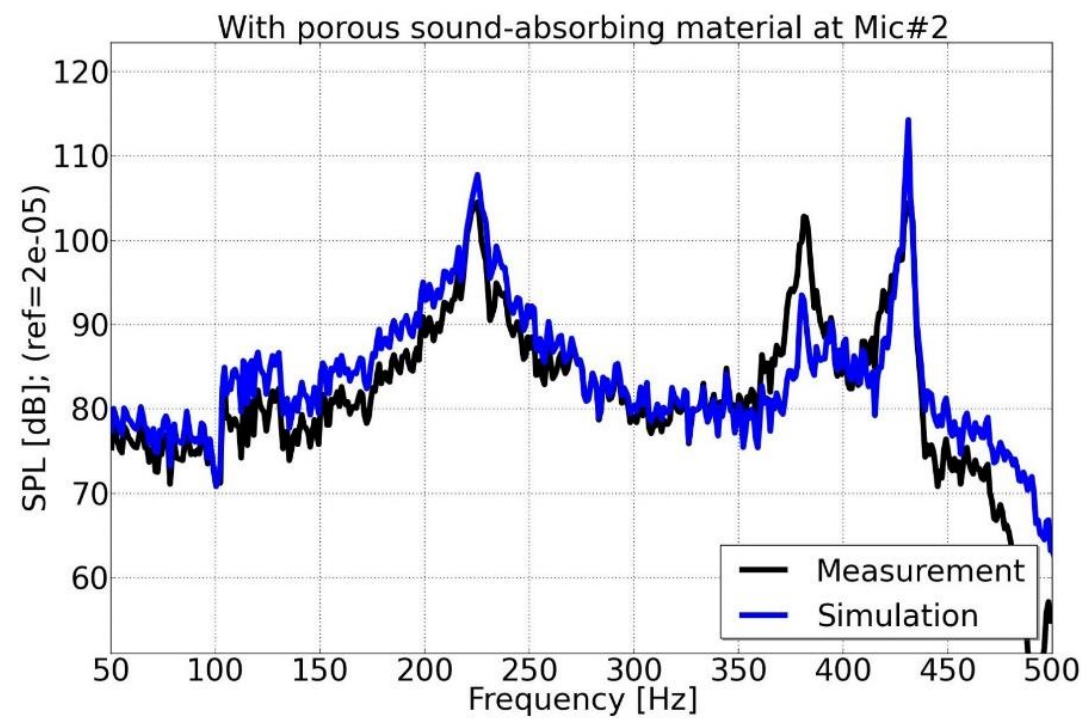

(b)

Figure 7 Comparison of the sound pressure response of the experimental method and the finite element model, for the coupled plate cavity sy stem with porous sound absorbing material: 
(a) sound pressure response of Mic\#1 to a point force excitation; (b) sound pressure response of $\mathrm{Mic \# 2}$ to a point force excitation.

The results obtained indicate reasonable agreement between the experiment and the FE model. The cavity interior Sound Pressure Level (SPL) is reduced by appending porous sound absorbing material by a similar amount in both the experiment and the FE model.

\section{Conclusions}

An appropriate simple coupled acoustic model is developed for studying the effect of the porous sound absorbing material on the noise propagation into a rectangular box cavity. In this paper, it is experimentally and numerically confirmed that the resonance peaks caused by the vibrating plate modes and the cavity modes can be reduced by applying porous sound absorbing material. The cavity sound pressure level is reduced by a similar amount in both the experiments and the simulations.

\section{Acknowledgments}

The authors would like to thank Excellerate Australia Ltd (Australia) and Futuris Automotive Group (Australia) for their financial support for this research. Zhengqing Liu is grateful to Mr. Peter Tkatchyk (Bundoora Campus, RMIT University) in preparing a series of experiments.

\section{References}

Allard, J.F. and Atalla, N. (2009) 'Propagation of sound in porous media: Modelling sound absorbing materials', John Wiley and Sons, Ltd.

Allard, J.F. and Champoux, Y. (1992) 'New empirical equations for sound propagation in rigid frame fibrous materials', The Journal of the Acoustical Society of America, Vol. 91, No. 6, pp.3346-3353.

Atalla, N. and Panneton, R. (1996) 'The effect of multilayer sound-absorbing treatments on the noise field inside a plate backed cavity', Noise Control Engineering Journal, Vol. 44, No. 5, pp.235-243.

Atalla, N., Amédin, C.K. and Sgard, F. (2003) 'Numerical and Experimental Investigation of the Vibro-Acoustics of a Plate Backed Cavity Coated With an Heterogeneous Porous Material', SAE Technical Paper, 2003-01-1453, doi:10.4271/2003-01-1453.

Bécot, F.-X. and Sgard, F. (2006) 'On the use of poroelastic materials for the control of the sound radiated by a cavity backed plate', The Journal of the Acoustical Society of America, Vol. 120, No. 4, pp.2055-2066.

Bécot, F.-X., Jaouen, L. and Sgard, F. (2011) 'Noise control strategies using composite porous materials-Simulations and experimental validations on plate/cavity systems', Noise Control Engineering Journal, Vol. 59, No. 5, pp.464-475. 
Biot, M.A. (1956a) 'Theory of propagation of elastic waves in a fluid-saturated porous solid, I. Low-frequency range', The Journal of the Acoustical Society of America, Vol. 28, No. 2, pp.168-178.

Biot, M.A. (1956b) 'Theory of propagation of elastic waves in a fluid-saturated porous solid, II. Higher-frequency range, The Journal of the Acoustical Society of America, Vol. 28, No. 2, pp.179-191.

Biot, M.A. (1962) 'Generalized theory of acoustic propagation in porous dissipative media', The Journal of the Acoustical Society of America, Vol. 34, No. 5, pp.1254-1264.

Champoux, Y. and Allard, J.F. (1991) 'Dynamic tortuosity and bulk modulus in air-saturated porous-media', Journal of Applied Physics, Vol. 70, No. 4, pp.1975-1979.

Citarella, R., Federico, L. and Cicatiello, A. (2007) 'Modal acoustic transfer vector approach in a FEM-BEM vibro-acoustic analysis', Engineering Analysis with Boundary Elements, Vol. 31, No. 3, pp.248-258.

Craggs, A. (1978) 'A finite element model for rigid porous absorbing materials', Journal of Sound and Vibration, Vol. 61, No. 1, pp.101-111.

Cremer, L. and Heckl, M. (1988) 'Structure-borne sound: structural vibrations and sound radiation at audio frequencies', Springer-Verlag.

Dowell, E,H. and Voss, H,M. (1963) 'The effect of a cavity on panel vibration', The American Institute of Aeronautics and Astronautics (AIAA. Journal), Vol. 1, No. 2, pp.476-477.

Dowell, E.H., Gorman, G.F. and Smith, D.A. (1977) 'Acoustoelasticity: general theory, acoustic natural modes and forced response to sinusoidal excitation, including comparisons with experiment', Journal of Sound and Vibration, Vol. 52, No. 4, pp.519-542.

Du, J.T., Li, W.L., Liu, Z.G., Xu, H.A. and Ji, Z.L. (2011) 'Acoustic analysis of a rectangular cavity with general impedance boundary conditions', The Journal of the Acoustical Society of America, Vol. 130, No. 2, pp.807-817.

Du, J.T., Li, W.L., Xu, H.A. and Liu, Z.G. (2012) 'Vibro-acoustic analy sis of a rectangular cavity bounded by a flexible panel with elastically restrained edges', The Journal of the Acoustical Society of America, Vol. 131, No. 4, pp.2799-2810.

Easwaran, V., Lauriks, W. and Coyette, J.P. (1996) 'Displacement-based finite element method for guided wave propagation problems: application to poroelastic media', The Journal of the Acoustical Society of America, Vol. 100, No. 5, pp.2989-3002.

Elwali, W., Li, M. and Lim, T.C. (2012) 'Vibro-acoustic computation of irregular cavities using a combined analytical-finite element approach with application to vehicle interior acoustics', International Journal of Vehicle Noise and Vibration, Vol. 8, No. 2, pp.136-150.

Guy, R.W. and Bhattacharya, M.C. (1973) 'The transmission of sound through a cavity backed finite plate', Journal of Sound and Vibration, Vol. 27, No. 2, pp.207-223.

Guy, R.W. (1979) 'The response of a cavity backed panel to external airborne excitation; a general analy sis', The Journal of the Acoustical Society of America, Vol. 65, No. 3, pp.719-731.

Hopkins, C. (2007). 'Sound Insulation', Butterworth-Heinemann.

Johnson, D.L., Koplik, J. and Dashen, R. (1987) 'Theory of dynamic permeability and tortuosity in fluid-saturated porous-media', Journal of Fluid Mechanics, Vol. 176, pp.379-402.

Kang, Y.J. and Bolton, J.S. (1995) 'Finite element modeling of isotropic elastic porous materials coupled with acoustic finite elements', The Journal of the Acoustical Society of America, Vol. 98, No. 1, pp.635-643.

Keltie, R.F. and Peng, H. (1987) 'The effects of modal coupling on the acoustic power radiation from panels', Journal of Vibration and Acoustic, Vol. 109, pp.48-54.

Lafarge, D., Lemarinier, P., Allard, J.F. and Tarnow, V. (1997) 'Dynamic compressibility of air in porous structures at audible frequencies', The Journal of the Acoustical Society of America, Vol. 102, No. 4, pp.1995-2006.

Lee, Y.Y. (2002) 'Structural-acoustic coupling effect on the nonlinear natural frequency of a rectangular box with one flexible plate', Applied Acoustics, Vol. 63, No. 11, pp.1157-1175.

Li, Y.Y. and Cheng, L. (2006) 'Vibro-acoustic analysis of a rectangular-like cavity with a tilted wall’, Applied Acoustic, Vol. 68, pp.739-751. 
Liu, Z., Fard. M. and Davy, J.L. (2015a) 'The effects of porous materials on the noise inside a box cavity', The 22nd International Congress on Sound and Vibration (ICSV22), Florence, Italy, 12-16 July 2015.

Liu, Z., Fard. M. and Jaza, R. (2015b) 'Development of an acoustic material database for vehicle interior trims', SAE Technical Paper, doi:10.4271/2015-01-0046.

Liu, Z., Fard. M. and Davy, J.L. (2016a) 'Acoustic properties of the porous material in a car cabin model', The 23rd International Congress on Sound and Vibration (ICSV23), Athens, Greece, 10-14 July 2016.

Liu, Z., Zhan, J., Fard. M. and Davy, J.L. (2016b) 'Acoustic properties of a porous polycarbonate material produced by additive manufacturing', Materials Letters, Vol. 181, pp.296-299.

Oldham, D.J. and Hillarby, S.N. (1990) 'The acoustical performance of small close fitting enclosures, Part 1: Theoretical models', Journal of Sound and Vibration, Vol. 150, No. 2, pp.261-281.

Panneton, R., Atalla. and Charon, F. (1995) 'A finite element formulation for the vibro-acoustic behavior of double plate structures with cavity absorption', Canadian Aeronautics and Space Journal, Vol. 41, pp.5-12.

Panneton, R. (2007) 'Comments on the limp frame equivalent fluid model for porous media', The Journal of the Acoustical Society of America (Express Letters), Vol. 122, No. 6, pp.217-222.

Pan, J. and Bies, D.A. (1990a) 'The effect of fluid-structural coupling on sound waves in an enclosure-Theoretical part', The Journal of the Acoustical Society of America, Vol. 87, No. 2, pp.691-707.

Pan, J. and Bies, D.A. (1990b) 'The effect of fluid-structural coupling on sound waves in an enclosure-Experimental part', The Journal of the Acoustical Society of America, Vol. 87, No. 2, pp.708-717.

Popo, L.D. (1971) 'On the transmission of sound through finite closed shells: Statistical energy analysis, modal coupling and non-resonant transmission', The Journal of the Acoustical Society of America, Vol. 50, pp.1004-1018.

Pretlove, A.J. (1956a) 'Free vibrations of a rectangular panel backed by a closed rectangular cavity', Journal of Sound and Vibration, Vol. 2, No. 3, pp.197-209.

Pretlove, A.J. (1965b) 'Forced vibrations of a rectangular panel backed by a closed rectangular cavity', Journal of Sound and Vibration, Vol. 3, No. 3, pp.252-261.

Pretlove, A.J. and Craggs, A. (1970) 'A simple approach to coupled panel-cavity vibrations', Journal of Sound and Vibration, Vol. 11, No. 2, pp.207-215.

Qaisi, M.I. (1988) 'Free vibration of a rectangular plate-cavity system', Applied Acoustic, Vol. 24, No. 1, pp.49-61.

Rumpler, R., Deü, J.F. and Göransson, P. (2012) 'A modal-based reduction method for sound absorbing porous materials in poro-acoustic finite element models', The Journal of the Acoustical Society of America, Vol. 132, No. 5, pp.3162-3179.

Rumpler, R., Göransson, P. and Deü, J.F. (2013) 'A residue-based mode selection and sorting procedure for efficient poroelastic modeling in acoustic finite element applications,' The Journal of the Acoustical Society of America, Vol. 134, No. 6, pp.4730-4741.

Seifzadeh, A., Pietrzyk, A., Göransson, P. and Ramakrishnan, R. (2014) 'Effect of coupling between passenger compartment and trunk of a car on coupled system natural frequencies using acoustic frequency response function', Applied Acoustics, Vol. 76, pp.310-318.

Tanaka, N., Takara, Y. and Iwamoto, H. (2012) 'Eigenpairs of a coupled rectangular cavity and its fundamental properties', The Journal of the Acoustical Society of America, Vol. 131, No. 3, pp.1910-1921.

Yamamoto, T., Maruy ama, S., Nishiwaki, S. and Yoshimura, M. (2009) 'Topology design of multimaterial soundproof structures including poroelastic media to minimize sound pressure levels, Computer Methods in Applied Mechanics and Engineering, Vol. 198, No.17-20, pp.14391455.

Zienkiewicz, O.C. and Shiomi, T. (1984) 'Dynamic behavior of saturated porous media: the generalized biot formulation and its numerical solution', International Journal for Numerical and Analytical Methods in Geomechanics, Vol. 8, No. 1, pp.71-96. 


\section{Figure 1}

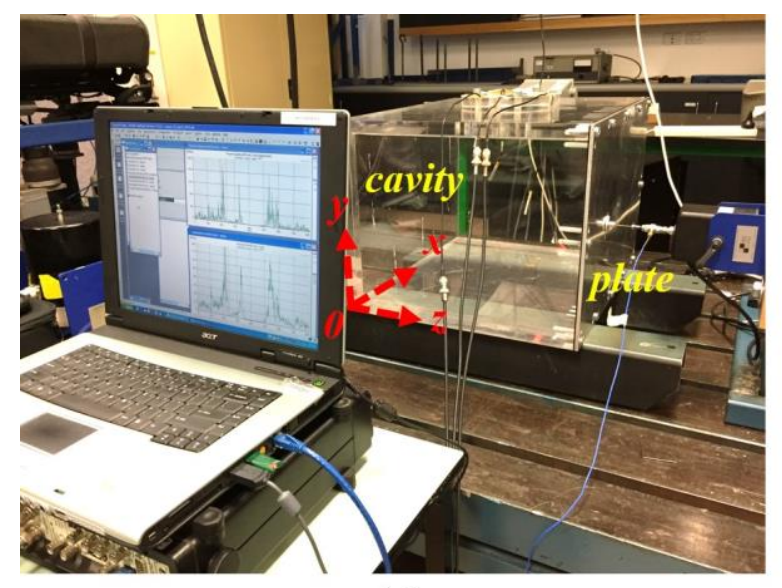

(a)

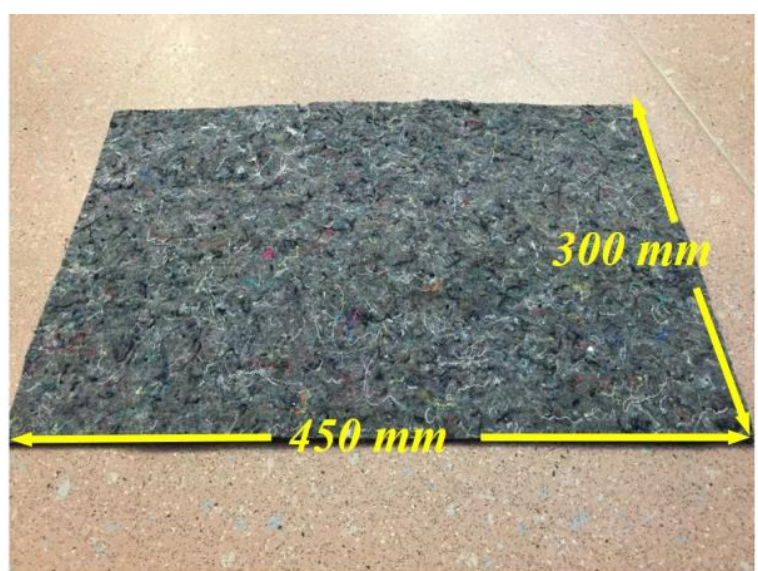

(b)

\section{Figure 2}

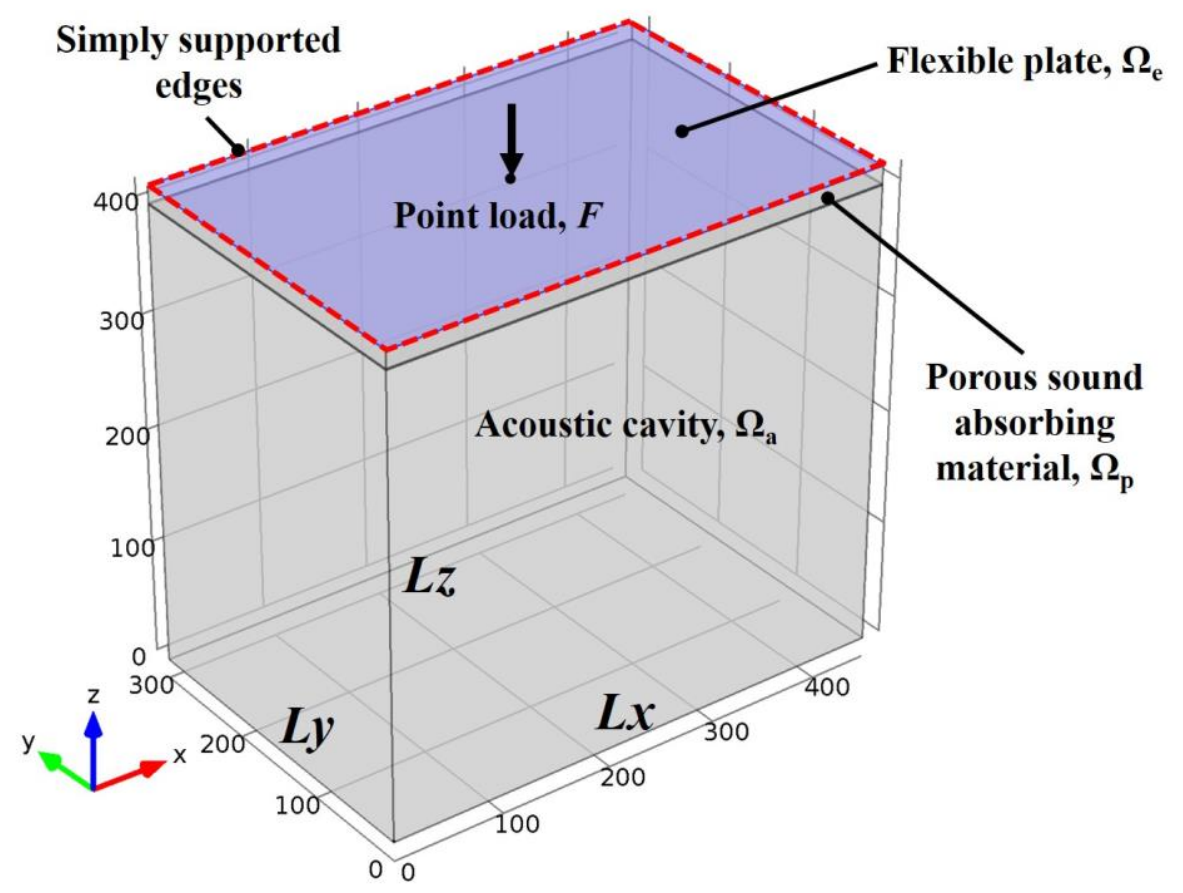




\section{Figure 3}

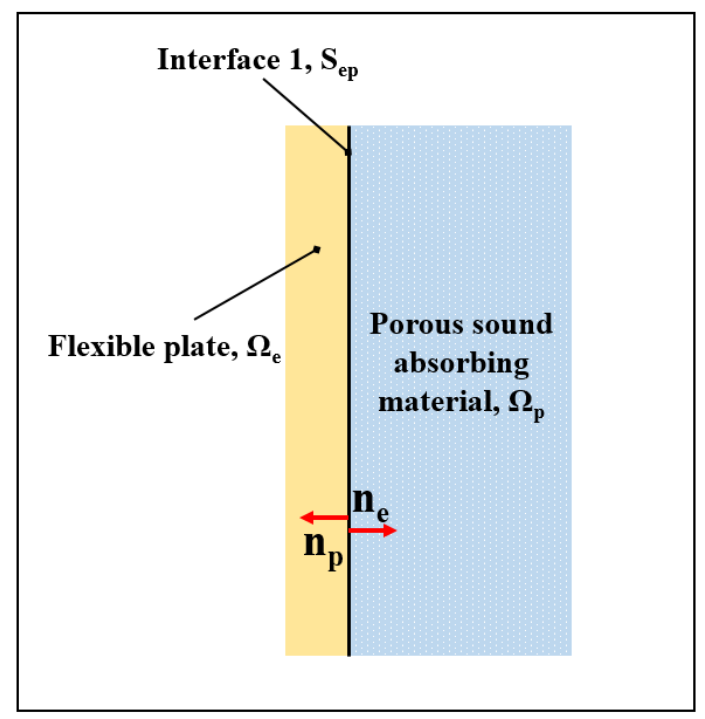

(a)

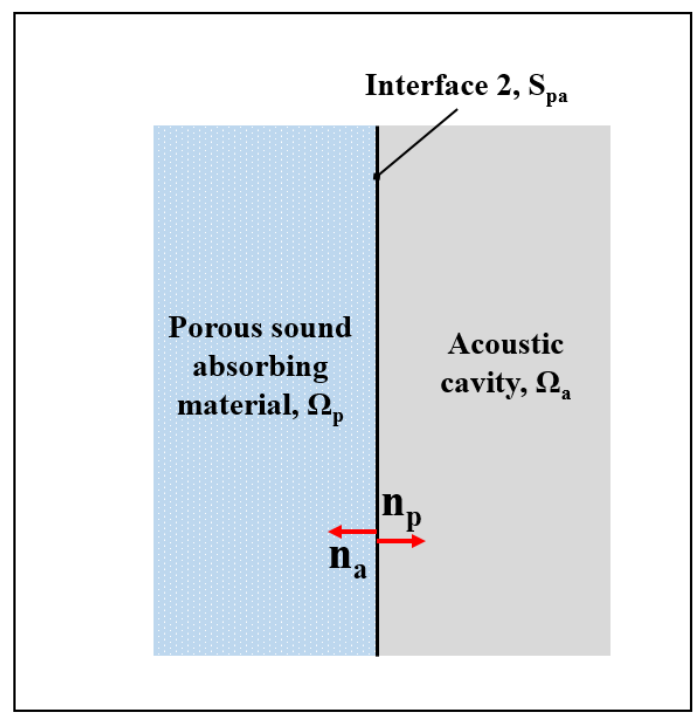

(b)

Figure 4

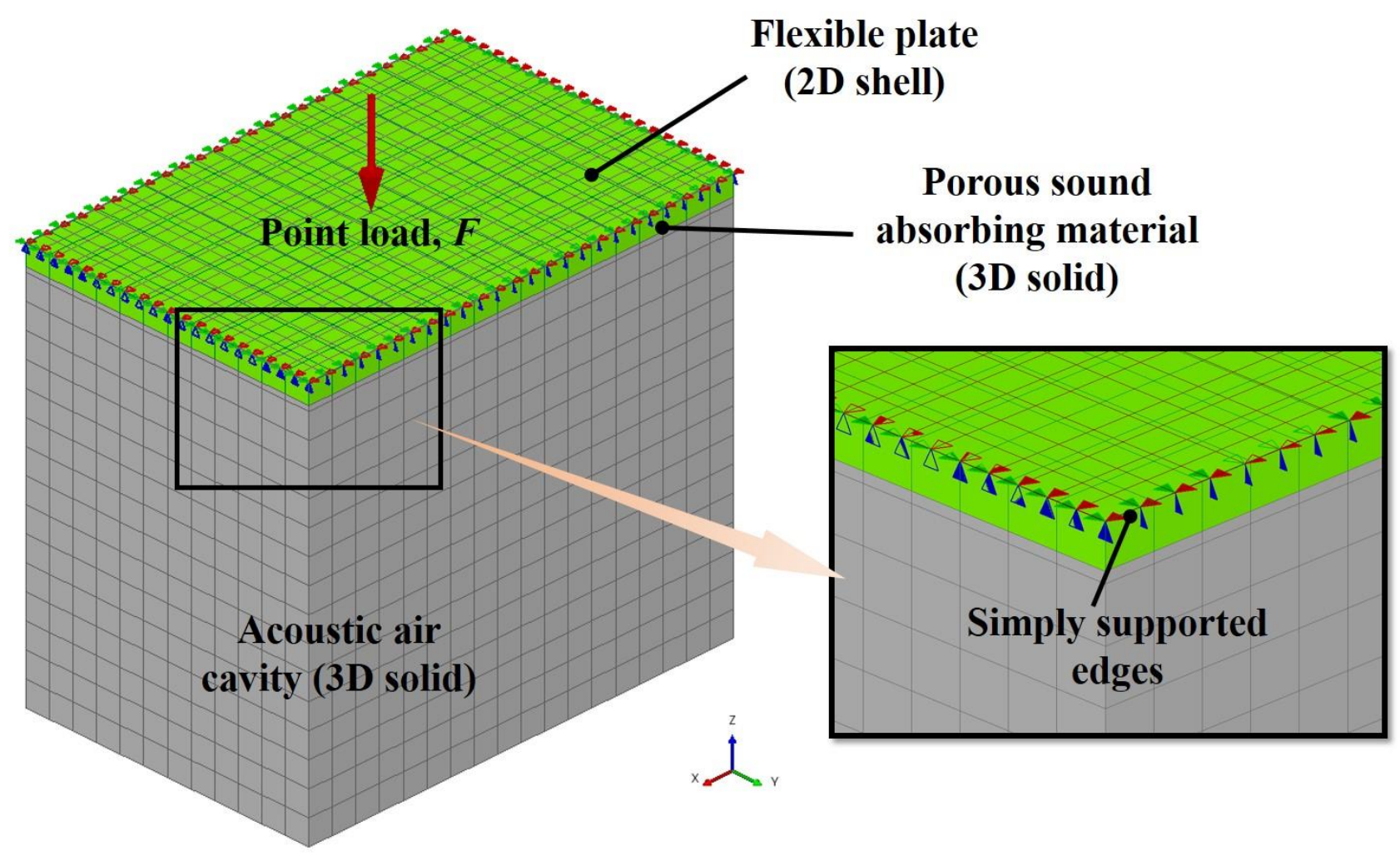




\section{Figure 5 (a)}

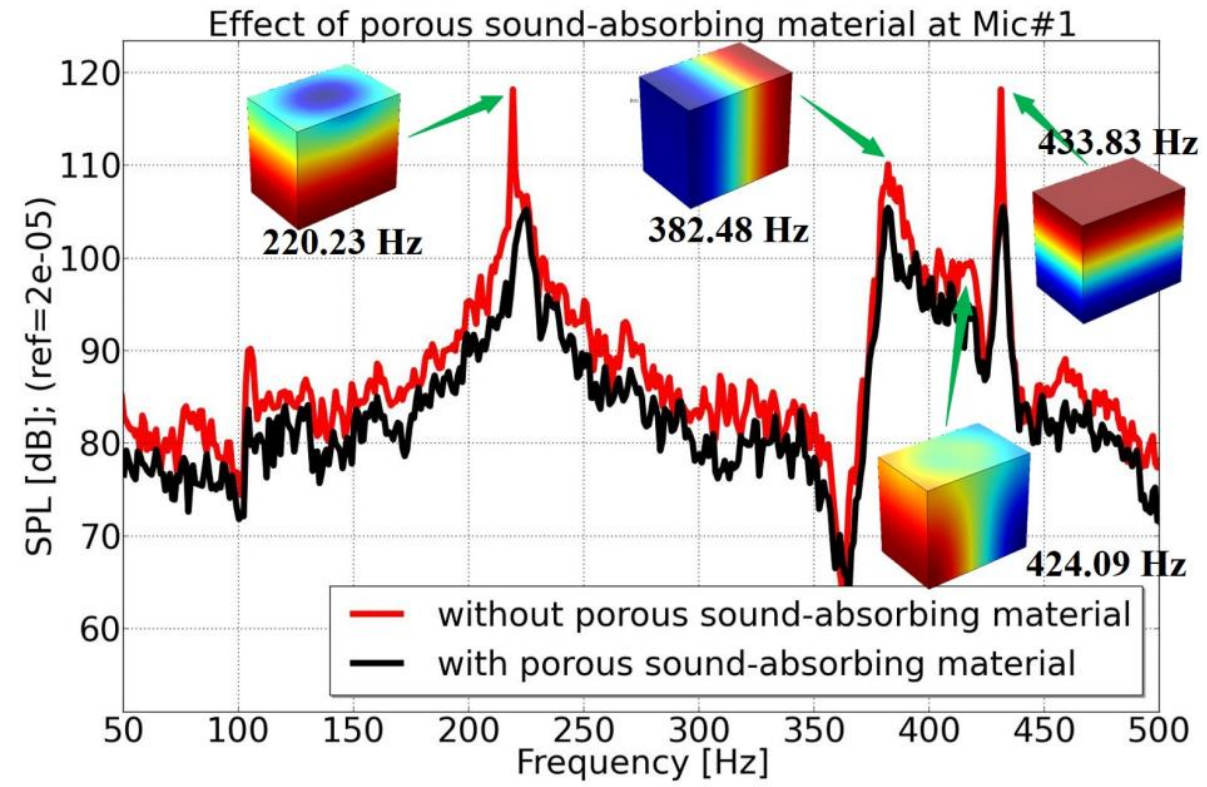

(a)

Figure 5 (b)

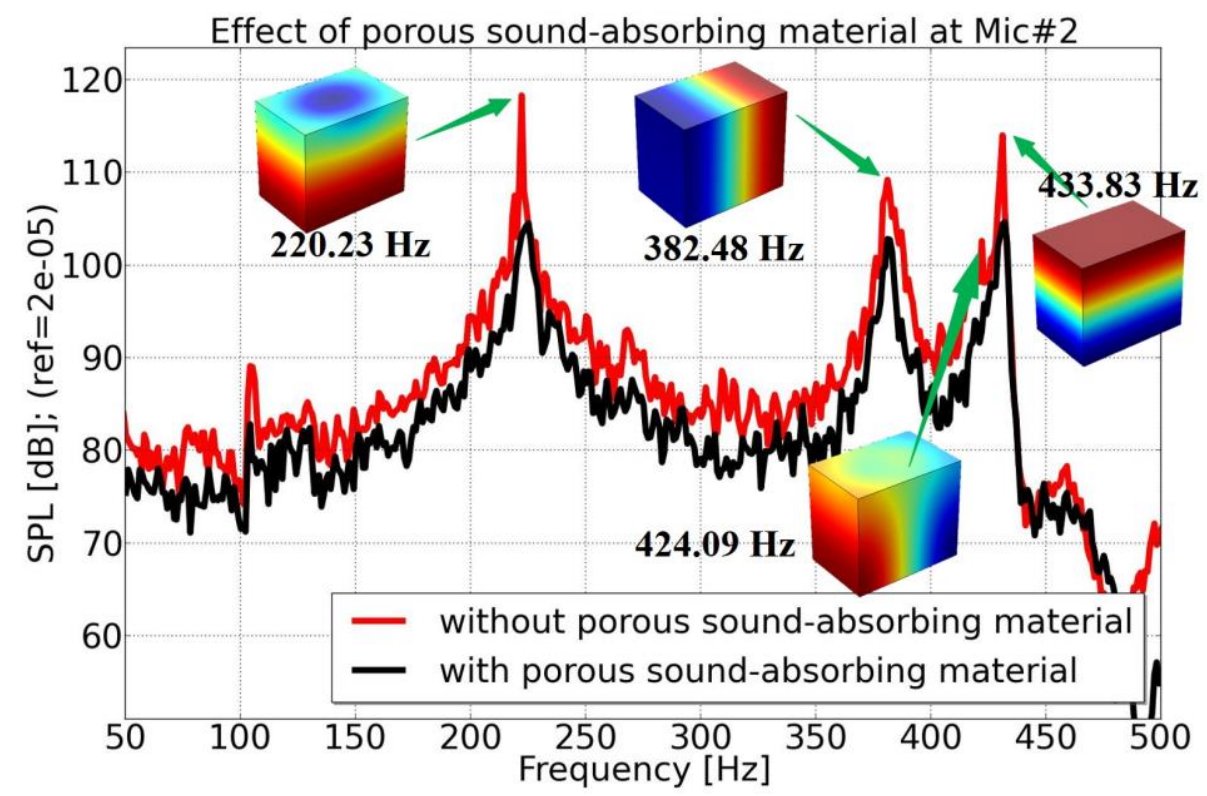

(b) 
Figure 6 (a)

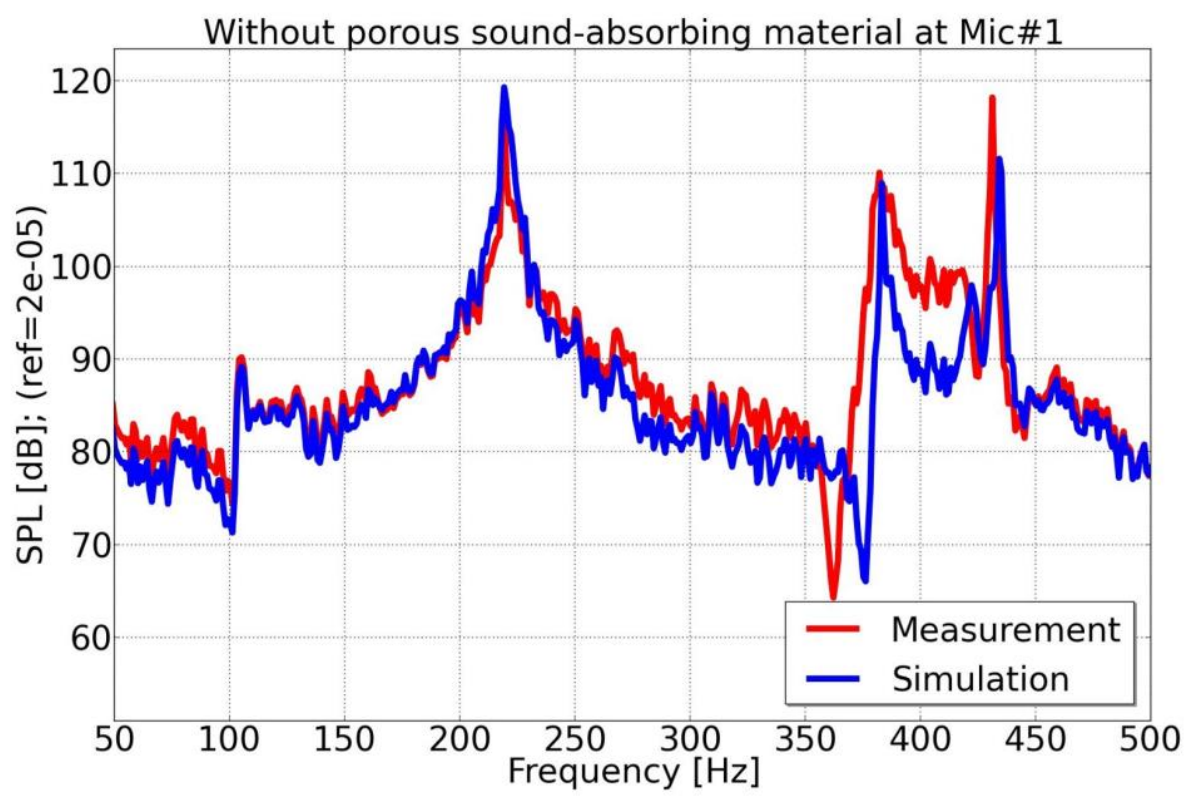

(a)

Figure 6 (b)

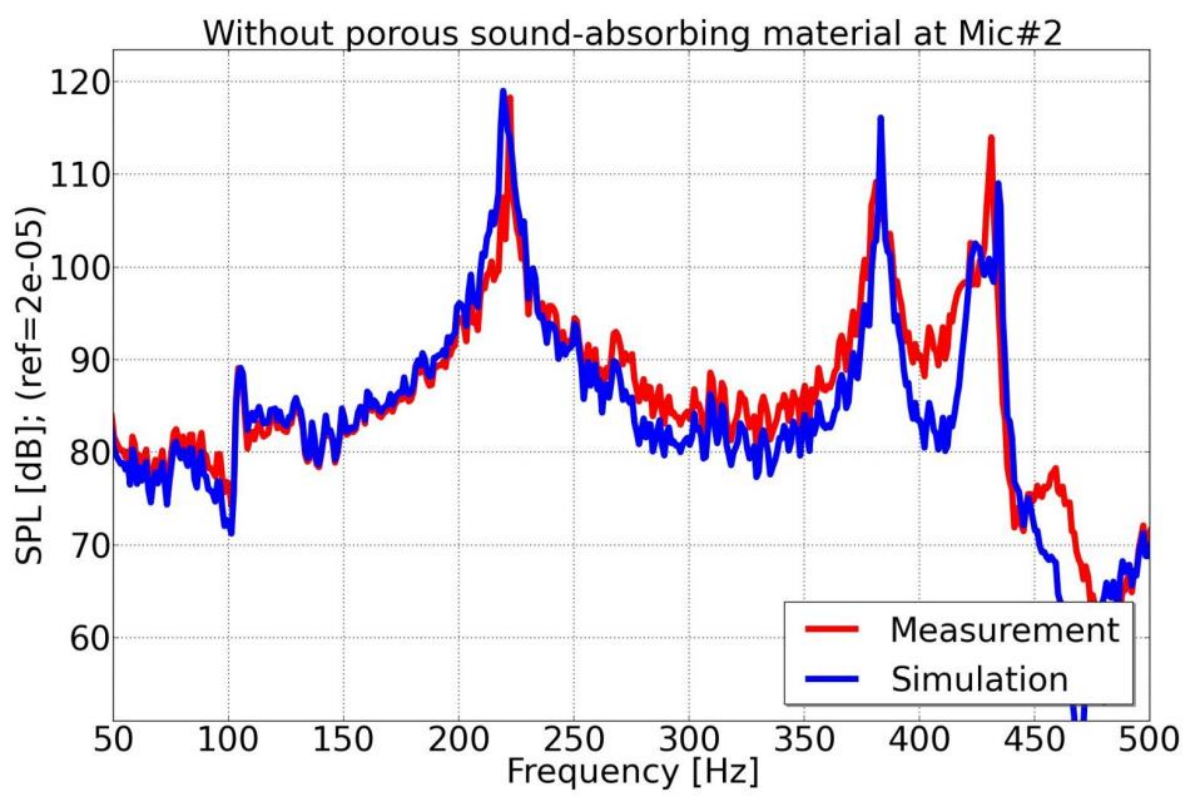

(b) 
Figure 7 (a)

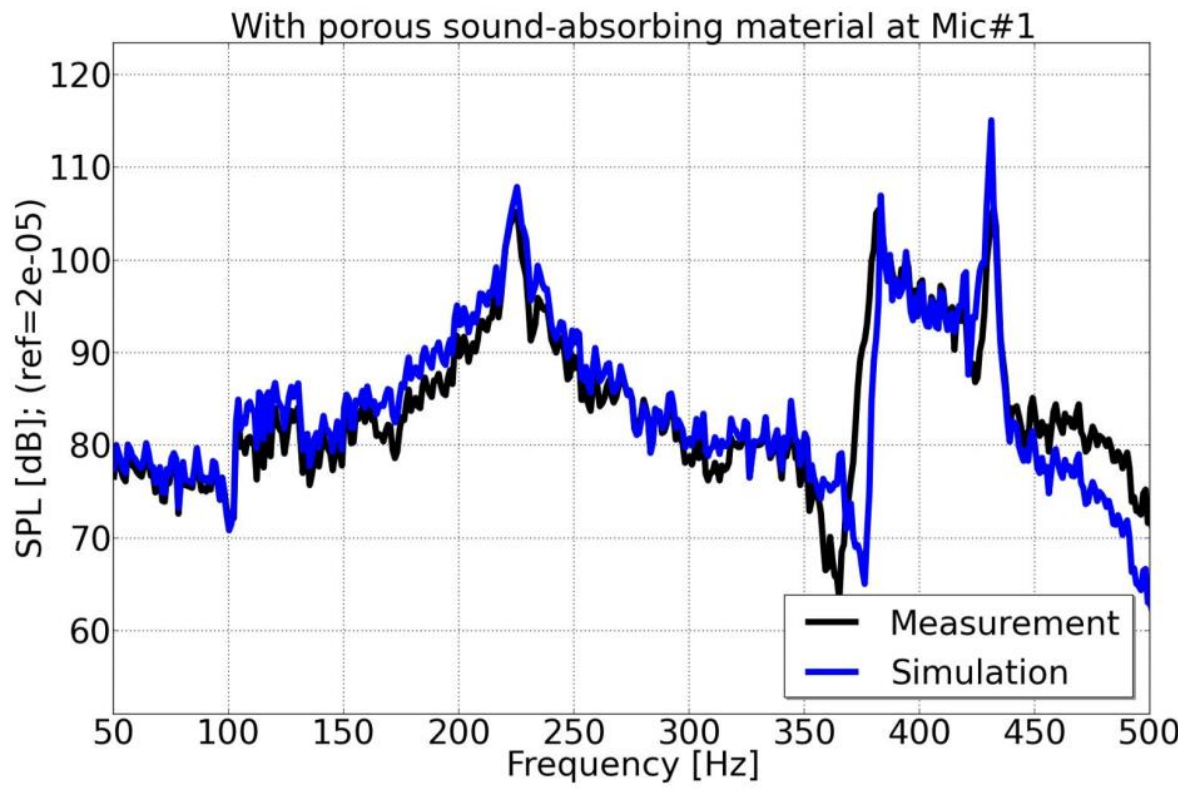

(a)

Figure 7 (b)

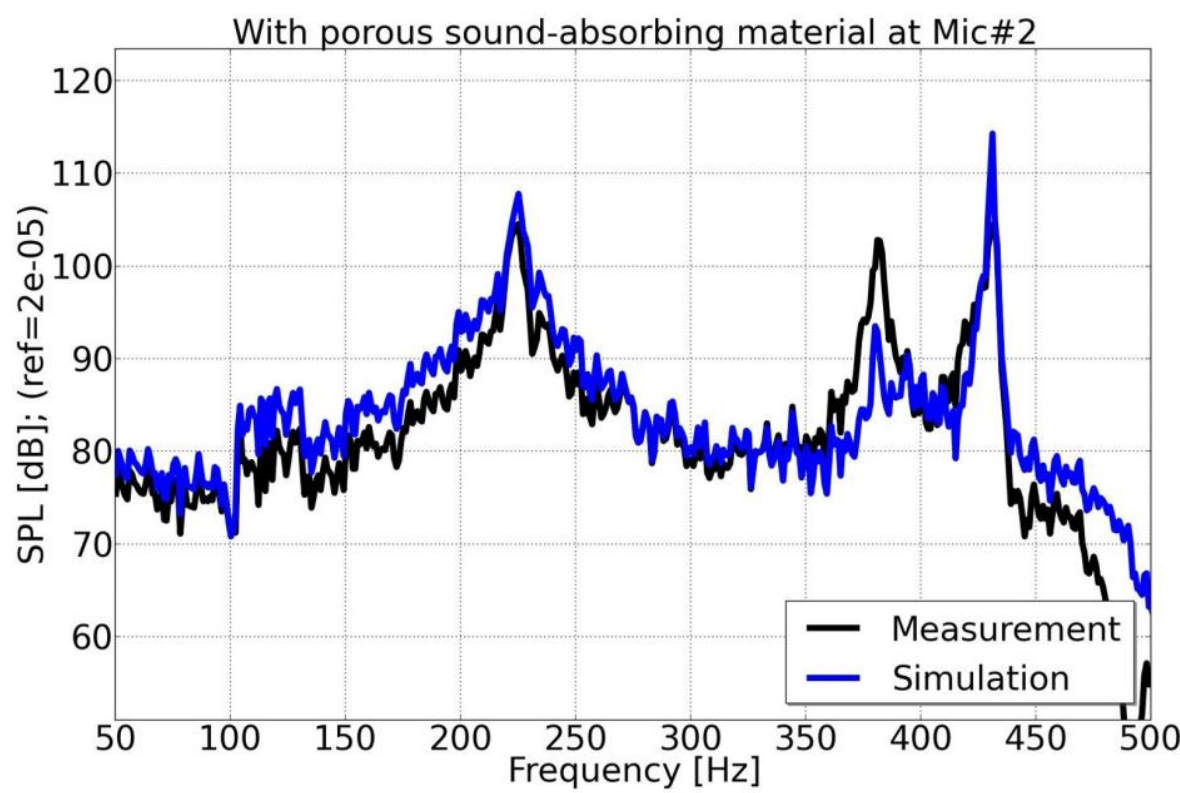

(b) 